\title{
ANAESTHESIA AND DEATH
}

\author{
Douglas GebBie, M.B., CH.B. ${ }^{\circ}$
}

MUCH INTEREST has been shown in deaths associated with anaesthesia by both the profession and lay public ever since Hannah Greener died on induction with chloroform in 1848. ${ }^{1}$ This first reported death occurred within eighteen months of the introduction of anaesthesia to clinical medicine. Certain sections of the medical profession have always been ready to attribute these unfortunate occurrences to therapeutic misadventure. Happily, others have been anxious to look further and seek more rational explanations.

It was felt that the publication of a review of deaths in an 800-bed general hospital in which anaesthesia played a part might be of wide interest and perhaps instructive as well.

Any attempt to assess the part played by anaesthesia in a fatality will be hedged with difficulties. These have been well summarized by Beecher \& Todd,? but in the final analysis there are three factors which must be taken into consideration: (1) patient disease, (2) surgery, (3) anaesthesia; and each of these must be weighed against the others when the cause of a particular death is being evaluated.

In this study consideration is given to all deaths in surgical and obstetrical patients occurring within ten days of surgery or delivery, and to those in which jaundice and liver failure or pulmonary complications were mentioned in either the death certificate or the autopsy report.

It is recognized that some delayed deaths in which anaesthesia played a part might have been missed, but every hospital medical record which satisfied the above criteria from 1958 to 1964 inclusive (i.e. 7 years) was scrutinized. Twenty-one cases were found in which anaesthesia was entirely or partially responsible for the death. These are summarized in Table $I$.

Over the seven years, 129,336 anaesthetics were given, 86,013 general anaesthetics, 25,706 locals, and 17,617 spinals and epidurals, producing a death rate of 1:6158. This compares with 1:1560 in Beecher and Todd's analysis, and 1:3955 reported by Clifton ${ }^{8}$ from Sydney, Australia, in 1963.

Closer examination will show that there was only one death where the anaesthetist alone appeared to have been responsible (case 6) and one where the recovery room staff, and thus vicariously the anaesthetist, could be blamed (case 1).

There were three cases of aspiration (nos. 8, 12, and 21) and two cases of circulatory collapse on moving the patient from the operating table to the stretcher at the conclusion of surgery (nos. 13 and 15), but the major cause of death was respiratory failure (cases $2,3,5,16,18,19$, and 20 ).

Inadequate pre-operative assessment was also of some moment in eight cases

'Department of Anaesthesia, St. Joseph's Hospital, Hamilton, Ont. 
(nos. 7, 9, 10,14,16,17, 18, and 20), and other unidentified and unidentifiable disease in one case (case 11). In three cases (nos. 2, 10, and 19), the cause of death was obscure and is open to speculation. In one case (no. 4), hypovolaemia occurred and could not be corrected owing to an administrative misunderstanding.

Thus, in order of frequency of occurrence, the list would read:

$\begin{array}{ll}\text { Repiratory failure } & 7 \\ \text { Hypovolaemia } & 4 \\ \text { Regurgitation or vomiting } & \\ \quad \text { with aspiration } & 3 \\ \text { Movement with circulatory } & \\ \quad \text { collapse } & 2 \\ \begin{array}{l}\text { Postoperative respiratory } \\ \text { obstruction }\end{array} & 1\end{array}$

\section{Discussion}

In the classification of 1000 deaths from the United Kingdom in 1956, Edwards ${ }^{4}$ listed the commonest causes as regurgitation and vomiting, circulatory failure associated with sodium thiopentone, obvious under-transfusion, and postoperative respiratory obstruction.

In 1964, however, Dinnick ${ }^{5}$ classified a further 600 deaths from the United Kingdom and found the emphasis quite changed. By far the largest number now had died as a result of an uncorrected hypovolaemia, and this was followed by under-ventilation, regurgitation and vomiting, and collapse with thiopentone, in that order.

Clifton in the meantime (1963), had listed inhalation of vomitus, respiratory obstruction, circulatory collapse after thiopentone, anaesthetic overdosage, and respiratory insufficiency. These findings are compared and contrasted in Table II.

It must be remembered that there is a greater awareness now among anaesthetists of the importance of reducing the dose of thiopentone for the induction of sick patients, or indeed, of avoiding its use altogether; in this hospital fatal circulatory collapse resulting from thiopentone has not been noted.

In spite of the provision of a recovery room with a well-trained staff, there was one death attributable to postoperative respiratory obstruction. At least the danger emphasized by Edwards, ${ }^{4}$ of anaesthetized patients being wheeled to distant parts of the hospital, often along dark corridors by junior staff members, has been avoided in this institution.

But our old friends, or enemies, crop up again. The prominence given to hypovolaemia by Dinnick shows that there is now a greater recognition of the importance of replacing and maintaining the circulating blood volume than in past years; and the fact that underventilation has received such widespread recognition is of special interest. It results from the ease with which blood-gas studies can now be done, and the consequent realization of the ready occurrence of hypercarbia, and sometimes hypoxia, with their attendant dangers. Thus the peroperative and postoperative ventilation of patients is undertaken much 


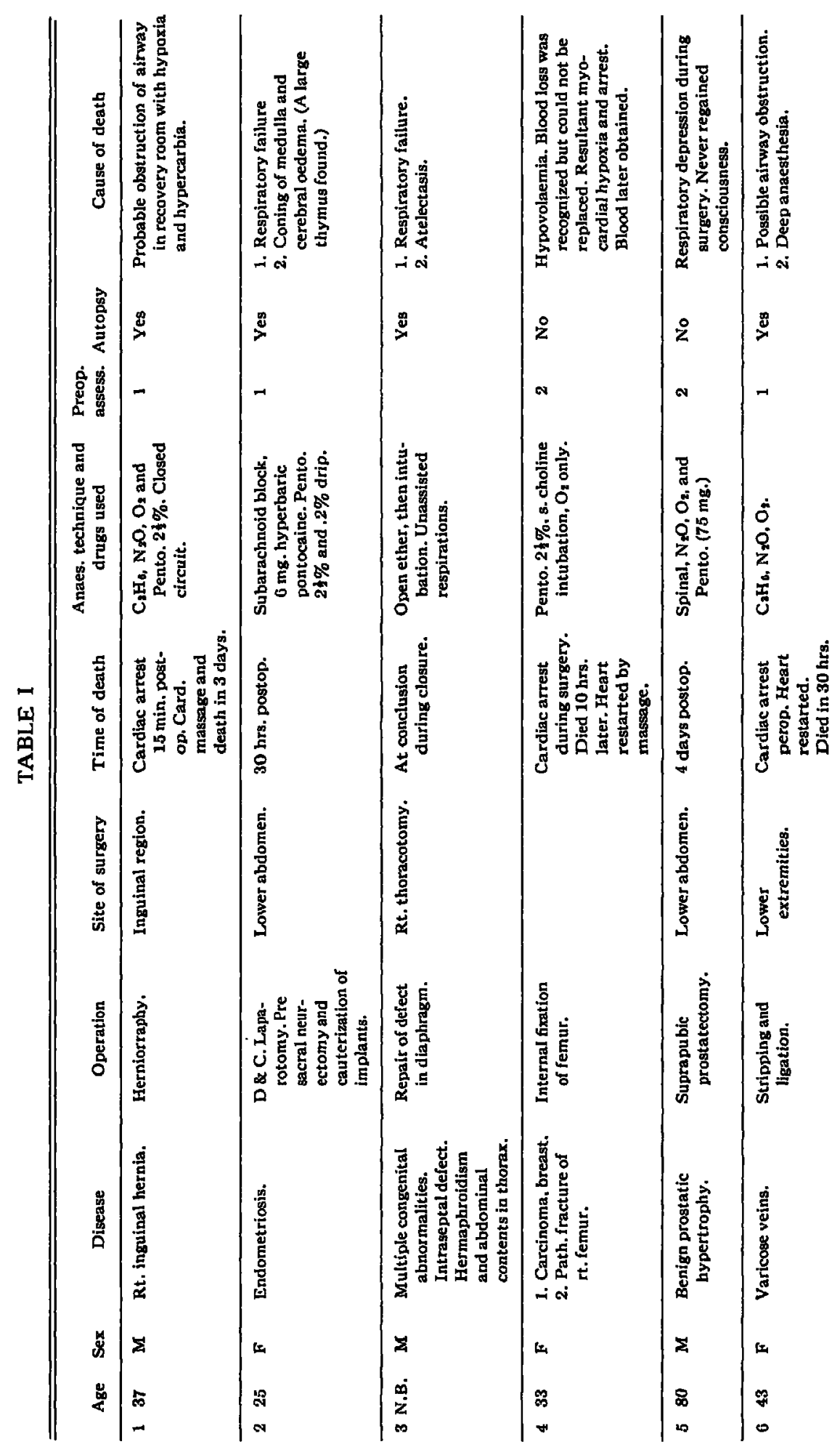




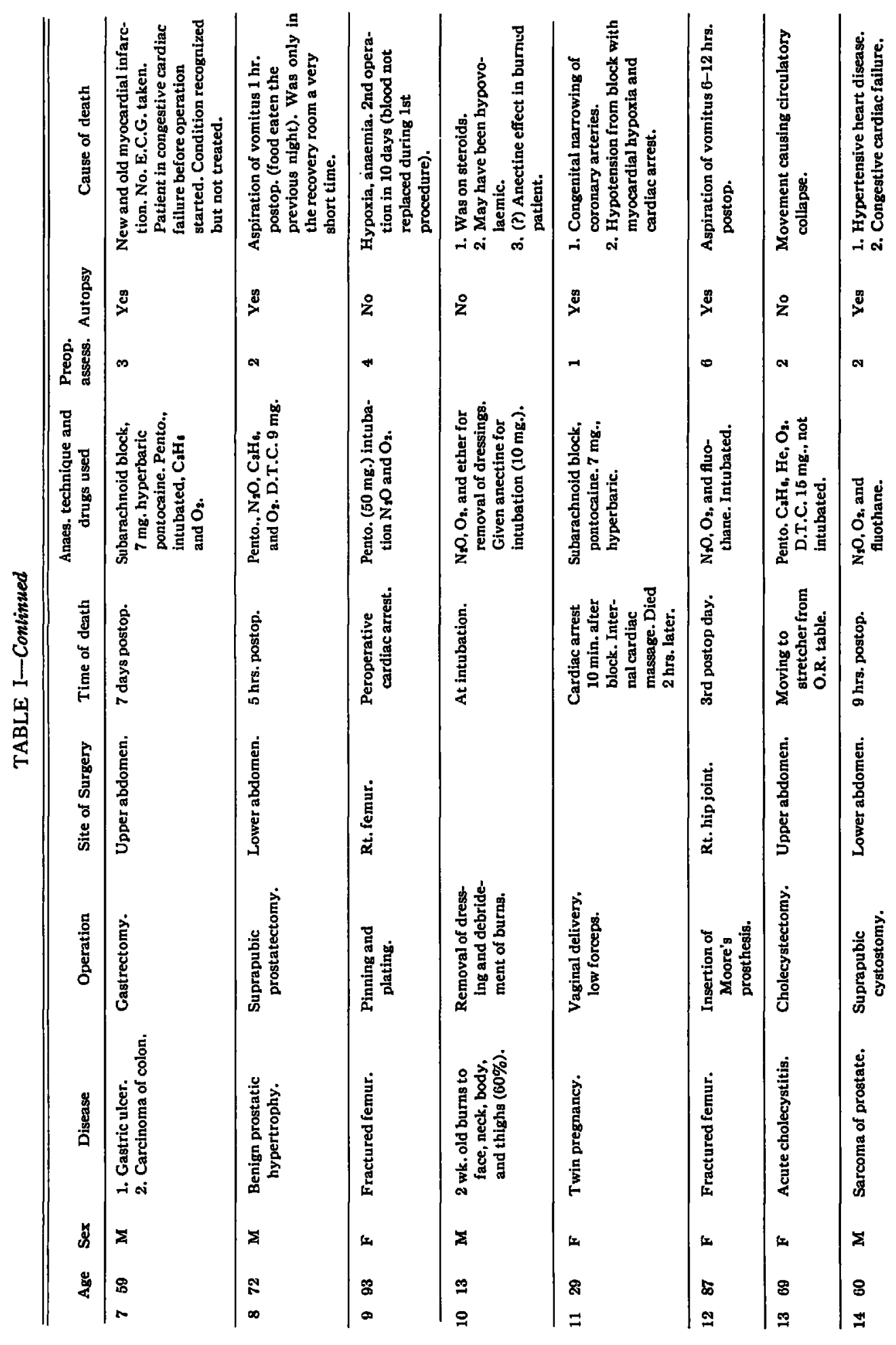




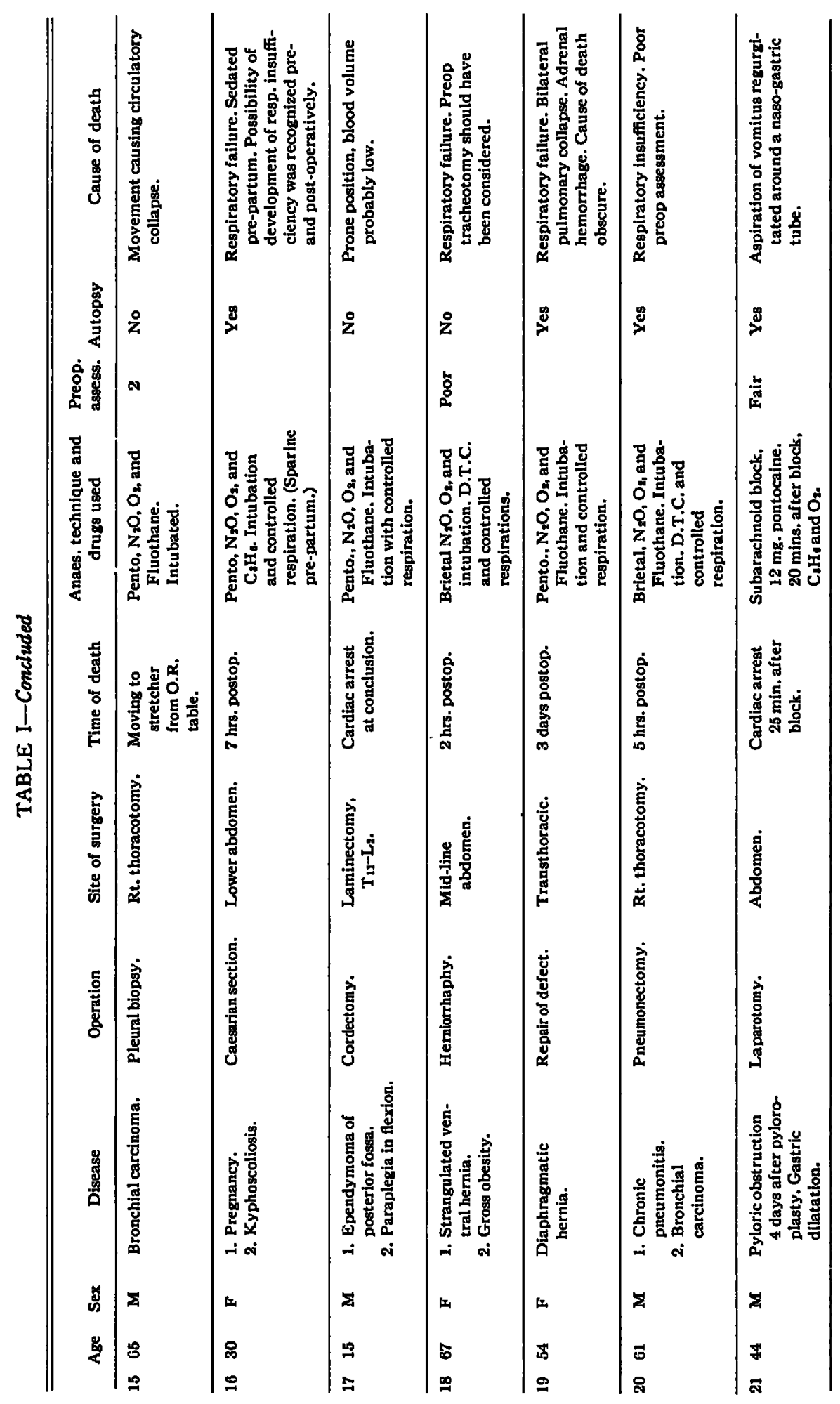


TABLE II

\begin{tabular}{|c|c|c|c|c|}
\hline & Edwards (1956) & Clifton (1963) & Dinnick (1964) & This report (1965) \\
\hline 1 & $\begin{array}{l}\text { Regurgitation and } \\
\text { vomiting }\end{array}$ & $\begin{array}{l}\text { Regurgitation and } \\
\text { vomiting }\end{array}$ & Low blood volume & Respiratory failure \\
\hline 2 & $\begin{array}{l}\text { Overdose i.v. } \\
\text { barbiturates }\end{array}$ & $\begin{array}{l}\text { Respiratory } \\
\text { obstruction } \\
\text { postoperatively }\end{array}$ & Underventilation & Hypovolaemia \\
\hline 3 & $\begin{array}{l}\text { Obvious under- } \\
\text { transfusion }\end{array}$ & $\begin{array}{l}\text { Circulatory } \\
\text { collapse after } \\
\text { i.v. barbiturates }\end{array}$ & $\begin{array}{l}\text { Regurgitation and } \\
\text { vomiting }\end{array}$ & $\begin{array}{l}\text { Regurgitation and } \\
\text { vomiting }\end{array}$ \\
\hline 4 & $\begin{array}{c}\text { Postoperative } \\
\text { respiratory } \\
\text { obstruction }\end{array}$ & $\begin{array}{l}\text { Anaesthetic } \\
\text { overdosage }\end{array}$ & $\begin{array}{l}\text { Collapse with } \\
\text { i.v. barbiturates }\end{array}$ & $\begin{array}{l}\text { Movement causing } \\
\text { circulatory } \\
\text { collaose }\end{array}$ \\
\hline 5 & $\begin{array}{c}\text { Mishaps with } \\
\text { intubation }\end{array}$ & $\begin{array}{l}\text { Respiratory } \\
\text { insufficiency }\end{array}$ & $\begin{array}{c}\text { Mishaps with } \\
\text { intubation }\end{array}$ & $\begin{array}{l}\text { Postoperative } \\
\text { respiratory } \\
\text { obstruction }\end{array}$ \\
\hline 6 & $\begin{array}{l}\text { Gross under- } \\
\text { ventilation }\end{array}$ & $\begin{array}{l}\text { Failure of } \mathrm{O}_{2} \\
\text { supply }\end{array}$ & During bronchoscopy & \\
\hline
\end{tabular}

more enthusiastically and effectively than heretofore, and failure in either of these spheres is more readily recognized as a cause of difficulty.

\section{Conclusions}

What lessons can be learned from the experiences presented in this paper? The anaesthesia in this hospital is that necessary for a wide range of surgical procedures, yet very few specialized techniques such as controlled hypotension are used. Thus the work is comparable with that done in most Canadian hospitals, the only difference being that all the anaesthetics, except for a few given by general practitioners for $\mathrm{T} \& \mathrm{~A}$, and for minor procedures in the emergency room, are administered by certificated anaesthetists.

Special consideration should be given to:

1. Careful preoperative assessment of the adequacy of the cardiac and respiratory systems.

2. The possibility of postoperative respiratory insufficiency developing insidiously, especially in the obese patient with an upper abdominal or thoracotomy incision.

3. The likelihood of the occurrence of circulatory failure in the hypovolaemic patient and the fact that this can be prevented by adequate intravenous therapy before and during operation.

4. The ever-present danger of aspiration.

5. The often unconsidered danger of circulatory collapse on change of position of the anaesthetized patient whose normal compensatory mechanisms are obtunded.

In conclusion, there are two items worth commenting upon:

1. No hepatoxic deaths have occurred in our institution during the years under consideration. Halothane is widely used in the operating rooms.

2. A death from meningitis occurred three weeks post-partum in a 23-year-old girl who received, by chance, a gas anaesthetic at the time of her delivery. The first symptoms of her fatal illness appeared three days post-partum. This in a 
hospital where 44 per cent of the patients receive a subarachnoid block for delivery!

\section{SUMMaRY}

A survey was made in an 800-bed general hospital of all deaths occurring within ten days of operation or delivery or at any time where mention was made of pulmonary complications or jaundice, during the seven years from 1958 to 1964 inclusive. Those in which it appeared that anaesthesia was wholly or partly responsible are described in detail. An attempt has been made to draw conclusions from these occurrences and to make suggestions for the avoidance of similar happenings in the future.

\section{ACKNOWLEDGMENTS}

The author wishes to acknowledge his gratitude to Dr. Kyles and Dr. F. Lepinskie for their help and encouragement in the preparation of this article, and to the Sisters of St. Joseph's Hospital and their staff for their assistance in gathering the relevant records and figures.

\section{REFERENCES}

1. Syres, W. S. Essays on the First Hundred Years of Anaesthesia. Vol. II. London: Livingston (1960), Pp. 18, 82, 96.

2. BEECHER, H. K. \& TODD, D. P. A Study of the Deaths Associated with Anaesthesia and Surgery. Springfield: Charles C. Thomas (1954), p. 43.

3. ClnftoN, B. S. \& Hotren, W. I. Deaths Associated with Anaesthesia. Brit. J. Anaesth. 35: 250 (1963).

4. Edwaros, G.; Monton, H. J. V.; PasK, E. A.; \& Wrum, W. D. Anaesthesia 11: 194 (1956).

5. Dinnıck, O. P. Deaths Associated with Anaesthesia. Anaesthesia 19: 536 (1964). 